\title{
Unused prescription drugs should not be treated like leftovers
}

\author{
Peter E. Wu MD, David N. Juurlink MD PhD
}

$\mathrm{O}$ n May 11, 2013, Public Safety Canada and the Canadian Association of Chiefs of Police coordinated the first National Prescription Drug Drop-Off Day, which resulted in the return of more than two tonnes of unused medications. ${ }^{1}$ This initiative was repeated on May 10, 2014. It was launched to reduce the amount of unused prescription drugs in Canadian households and, ultimately, drug-related harm. Herein, we provide some of the reasons why unused prescription drugs are so common, some of the problems associated with their use and the importance of the safe disposal of unused medications.

Many people report that they keep unused or expired medications in their homes. ${ }^{2}$ There are two main reasons for this practice. The first is inertia: it takes effort to discard something, but no effort to leave it where it is. The second is a natural inclination to keep something that might be useful later on, particularly if future procurement involves inconvenience or expense.

Patients may think that if a medication served a purpose previously, it might do so again. Analgesics may be the best example here, because people are often inclined to treat pain as soon as it arises. Opioids are often overprescribed, even for short-term pain. In a study involving 212 patients who underwent dermatologic surgery, one-third were prescribed opioids. Only $41 \%$ of the dispensed tablets were used, $86 \%$ of the patients did not take all of the prescribed medication, and more than $50 \%$ of these patients planned to keep their remaining tablets. ${ }^{3}$ Another familiar example is the misuse of antibiotics. A systematic review found that more than a third of patients did not complete their antibiotic course as prescribed, and unused antibiotics were taken by more than a quarter of the patients for new infections. ${ }^{4}$

Some patients may not appreciate the dangers of keeping unused prescription medications. ${ }^{2}$ For example, unused opioids, benzodiazepines and stimulants are major sources of misuse and diversion. A recent report by the Centre for Addiction and Mental Health underscores the importance of this issue: $15 \%$ of students in grades 7 to 12 in Ontario reported using prescription medications (most often opioids and stimulants) for recreation in the preceding year. ${ }^{5}$ The most common source of diverted opioids was unused tablets prescribed to someone else at home, typically a parent or sibling. ${ }^{5}$ Unused prescription drugs are sometimes brought to "pill parties" (also called "pharm" or "Skittles" parties), where adolescents experiment with pills they select from the pool of medications brought by partygoers. With opioids in particular, some products contain enough active ingredient in a single tablet to cause death in a naive patient, especially if mixed with other sedatives or alcohol. ${ }^{6}$

Another obvious concern is that patients may self-medicate for a new illness with medication previously prescribed for a different illness. Selfmedication with antibiotics is a common practice, most often for a sore throat. ${ }^{7}$ Because most sore throats are often caused by viral infection, the use of antibiotics in this setting confers risk without benefit, including drug-specific risks for the patient and the promotion of bacterial resistance. Patients with bacterial infections who use leftover antibiotics can delay medical assessment and obfuscate bacterial culture results, thereby hindering a correct diagnosis and the use of a more appropriate antibiotic.

Accidental ingestion of unused prescription medications by toddlers is a less widely appreciated risk. Between 2001 and 2008, more than 450000 cases of poisoning in children under six years of age were reported to US poison control centres. Of these, 95\% involved the ingestion of a prescription medication, which resulted in substantial morbidity and resource use (i.e., nonfatal injury, visit to the emergency department and admission to hospital), as well as 66 deaths. ${ }^{8}$
Competing interests: None declared.

This article was solicited and has not been peer reviewed.

Correspondence to: Peter Wu, pete.wu@mail.utoronto.ca

CMAJ 2014. DOI:10.1503 /cmaj.140222 
This study did not report the number of incidents specifically caused by leftover or expired prescription drugs, but these drugs are likely a risk factor for pediatric poisoning.

What can be done to avoid the problems associated with unused prescription drugs? It is sensible to encourage responsible disposal of unneeded or expired medications, but guidance on how to dispose of medications is lacking. Health Canada recommends that unused medications be returned to local pharmacies or municipal waste disposal centres and advises against the disposal of medications in the garbage or by flushing them down the toilet. ${ }^{9}$ In contrast, the US Food and Drug Administration recommends disposal in the garbage after the unused medications have been mixed with coffee grinds or cat litter to mask the drug or render it unpalatable. ${ }^{10}$ This method of disposal may be effective, but it involves some effort and is not without risk, as ingestions still may occur. ${ }^{11}$

The practice of flushing medications down the toilet is viewed by some as being unfriendly to the environment; however, the quantity of drugs and their metabolites that enter the environment from human waste is far greater than what might result from the flushing of medications. The concern that concentrations of drugs in water systems will cause harm to humans has not been proven. ${ }^{11}$ The disposal of medications by flushing is convenient and easy, even if it is viewed as unseemly, and may be appropriate for drugs that are prone to abuse. ${ }^{12}$

Some patients may be more comfortable returning their unused medications to the pharmacy. A national "drop-off day" for unused prescription drugs provides a way for safe disposal and it raises public awareness of the dangers associated with unused medications. However, patients may hoard their unused medications until the specified day, ${ }^{11}$ even though pharmacies will take unused medications at any time.

It is impractical to advocate for the disposal of all unused prescription drugs. Some chronic conditions require periodic treatment. Patients with allergies will have to take antihistamines as needed; recurrent migraines will need to be treated with either abortive therapy or short courses of analgesics; and some patients diagnosed with atrial fibrilllation will follow "pill-in-pocket" antiarrhythmic strategies. As with alcohol, cleaning solutions, tools and firearms, the safe storage of all drugs kept at home is common sense.

Finally, health care professionals have an important role in reducing the amount of unused medications in Canadian homes. Physicians can do their part by modifying their prescribing practices. Analgesics are often prescribed in greater quantities than patients will need, ${ }^{3}$ and courses of antibiotics are prescribed for longer than are warranted clinically. ${ }^{4}$ Pharmacists can play a role by advocating for the return of unused medications, particularly because of their increased prescribing privileges and the growing number of automatic refills that also add to the pool of unused medications. The problem of unused medications is partly our doing. Being part of the solution is easier than it might seem.

\section{References}

1. Chief Mark Mander (Chair, Drug Abuse Committee, Canadian Association of Chiefs of Police) at the Health Committee on February 6, 2014. Meeting \#12 in the 41st Parliament, 2nd sess. Available: http://openparliament.ca/committees/health/41-2/12 /chief-mark-mander-1/only/ (accessed 2014 Apr. 17).

2. Seehusen DA, Edwards J. Patient practices and beliefs concerning disposal of medications. J Am Board Fam Med 2006; 19:542-7.

3. Harris K, Curtis J, Larsen B, et al. Opioid pain medication use after dermatologic surgery: a prospective observational study of 212 dermatologic surgery patients. JAMA Dermatol 2013;149:317-21

4. Kardas P, Devine S, Golembesky A, et al. A systematic review and meta-analysis of misuse of antibiotic therapies in the community. Int J Antimicrob Agents 2005;26:106-13.

5. Boak A, Hamilton HA, Adlaf EM, et al. Drug use among Ontario students 1977-2013: detailed OSDUHS findings. (CAMH Research Document Series no. 36). Toronto (ON): Centre for Addiction and Mental Health; 2013.

6. Newfield M. Prescription drug deaths: two stories. CNN Health [Atlanta] 2012 Nov 19. Available: www.cnn.com/2012/11/15 health/deadly-dose-jackson-rummler (accessed 2014 Feb. 26).

7. Grigoryan L, Monnet DL, Haaijer-Ruskamp FM, et al. Selfmedication with antibiotics in Europe: a case for action. Curr Drug Saf 2010;5:329-32.

8. Bond GR, Woodward RW, Ho M. The growing impact of pediatric pharmaceutical poisoning. J Pediatr 2012;160:265-70.

9. Proper use and disposal of medication. Ottawa (ON): Health Canada; 2012. Available: http://healthycanadians.gc.ca/health-sante /medicine-medicament/disposal-defaire-eng.php (accessed 2014 Feb. 15).

10. How to dispose of unused medications. Silver Spring (MD): US Food and Drug Administration; 2013. Available: www.fda.gov /forconsumers/consumerupdates/ucm101653.htm (accessed 2014 Jan. 24).

11. Daughton CG. Drugs and the environment: stewardship sustainability. Report NERL-LV-ESD 10/081, EPA/600/R-10/106. Washington (DC): US Environmental Protection Agency; 2010. Available: www.epa.gov/nerlesd1/bios/daughton/APM200-2010 .pdf (accessed 2014 Jan. 24).

12. Medicines recommended for disposal by flushing. Silver Spring (MD): US Food and Drug Administration; 2013. Available: www .fda.gov/downloads/Drugs/ResourcesForYou/Consumers/Buying UsingMedicineSafely/EnsuringSafeUseofMedicine/SafeDisposal ofMedicines/UCM337803.pdf (accessed 17 Feb. 2014).

Affiliations: Department of Medicine (Wu, Juurlink), University of Toronto; Department of Medicine (Wu), University Health Network - Toronto General Hospital; Department of Medicine (Juurlink), Sunnybrook Health Sciences Centre; Institute for Clinical Evaluative Sciences (Juurlink), Toronto, Ont.

Contributors: Both authors contributed substantially to writing and revising and to the conception and design of the manuscript and approved the final version submitted for publication. 